\title{
CONF-940416--36
}

\section{ENVIRONMENTAL MICROCRACKING OF [NZP] TYPE CERAMICS}

T. B. Jackson

LoTEC, Inc.

Salt Lake City, UT 84119

W. D. Porter

Oak Ridge National Laboratory

Metals and Ceramics Division

Oak Ridge, TN 37831

\section{DISCLAIMER}

\begin{abstract}
This report was prepared as an account of work sponsored by an agency of the United States Government. Neither the United States Government nor any agency thereof, nor any of their employees, makes any warranty, express or implied, or assumes any legal liability or responsibility for the accuracy, completeness, or usefulness of any information, apparatus, product, or process disclosed, or represents that its use would not infringe privately owned rights. Reference herein to any specific commercial product, process, or service by trade name, trademark, manufacturer, or otherwise does not necessarily constitute or imply its endorsement, recommendation, or fayoring by the United States Government or any agency thereof. The views and opinions of authors expressed herein do not necessarily state or reflect those of the United States Government or any agency thereof.
\end{abstract}

\begin{abstract}
NZP ceramics (sodium zirconium phosphate and its crystal structure analogs) have very low thermal expansion through a large temperature range. Some compositions, with a high degree of thermal expansion anisotropy, are prone to microcracking upon cooling to room temperature. The onset of microcracking is a function of sintering temperature and hence grain size. Subsequent thermal cycling affects the thermal expansion behavior of highly anisotropic compositions due to microcrack healing. Recently it has been determined that this microcracking behavior can be delayed or enhanced by controlling the atmosphere in which the ceramic is heated and cooled. The effects of various atmospheres on the thermal expansion of isotropic and anisotropic [NZP] compositions are presented.
\end{abstract}

\section{INTRODUCTION}

NZP ceramics (sodium zirconium phosphate and its crystal structural analogs) are a relatively new class of low to ultra-low thermal expansion materials which have potential for high-temperature, high thermal shock resistance, applications. These applications include diesel engine exhaust port liners, molten metal filters, braze fixtures and thermal barrier coatings. Due to the unique open crystal structure of the prototype [NZP] composition, $\mathrm{NaZr}_{2} \mathrm{P}_{3} \mathrm{O}_{12}$, many ionic substitutions can be

The sebmitted menuscript has boen authored by a contrector of the U.S. Government under contract No. DEACO5-840R2 1400. Accordingly, the U.S. Government retsins a nonexchesive. royalty-ties license to putish or reproduce the pitished form of this cortitution, of thow others to do so, for U.S. Governinent purposes."

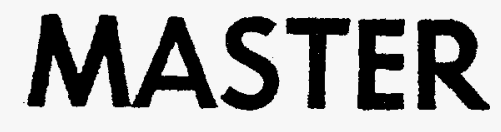




\section{DISCLAIMER}

Portions of this document may be illegible in electronic image products. Images are produced from the best available original document. 
made leading to numerous new compositions with tailored thermophysical properties [1]. While investigating the effect of substituting alkaline earths for sodium in the [NZP] structure (hexagonal with R3c space group symmetry), it was found that $\mathrm{CaZr}_{4} \mathrm{P}_{6} \mathrm{O}_{24}$ has a negative coefficient of thermal expansion (CTE) and $\mathrm{SrZr}_{4} \mathrm{P}_{6} \mathrm{O}_{24}$ has a positive CTE [2]. It was also determined that these compositions have opposite lattice expansion anisotropy. The $\mathrm{CTE}$ for $\mathrm{CaZ}_{4} \mathrm{P}_{6} \mathrm{O}_{24}$ is negative along the a-axis and positive for $\mathrm{SrZr}_{4} \mathrm{P}_{6} \mathrm{O}_{24}$; while for the $\mathrm{c}$-axis direction the opposite is true. Complete solid solution of $\mathrm{CaZr}_{4} \mathrm{P}_{6} \mathrm{O}_{24}$ and $\mathrm{SrZr}_{4} \mathrm{P}_{6} \mathrm{O}_{24}$ $\left(\mathrm{Ca}_{1-\mathrm{x}} \mathrm{Sr}_{\mathrm{x}} \mathrm{Zr}_{4} \mathrm{P}_{6} \mathrm{O}_{24}\right)$ can be achieved, with the mid-point composition exhibiting low CTE and very low anisotropy. Another substituted [NZP] has been developed in which barium is substituted for sodium and silicon replaces some of the phosphorous. A series of compositions $\left(\mathrm{Ba}_{1+x} \mathrm{Zr}_{4} \mathrm{P}_{6-2 \mathrm{x}} \mathrm{Si}_{2 \mathrm{x}} \mathrm{O}_{24}\right)$ can be made that exhibit bulk thermal expansion that ranges from positive to negative with varying degrees of lattice expansion anisotropy. The two compositional series described above are being investigated for their possible use as exhaust port liners for diesel engines. Knowledge of [NZP] thermophysical properties is essential for their successful implementation.

Part of the low thermal expansion behavior of these ceramics is attributable to the development of microcracks upon cooling from the sintering temperature [3]. Microcrack formation is due to the stresses associated with the axial thermal expansion anisotropy and it is dependent upon grain size [4]. During reheating of the ceramic, some of the crystallographic thermal expansion is taken up by closure and healing of the microcracks (at high temperatures) resulting in an apparent lower bulk thermal expansion as compared to the axial thermal expansion. When the ceramic is heated to temperatures above $600^{\circ} \mathrm{C}$ (which promotes crack healing) some subsequent amount of cooling is required before the internal stresses become sufficiently large to reinitiate microcrack formation [5]. This leads to a hysteresis in the thermal expansion curve as shown in Fig. 1. During characterization of the thermal expansion of the above compositional series up to $1250^{\circ} \mathrm{C}$, it was noticed that upon cooling to room temperature some of the test specimens did not recover to their initial pre-test length. By leaving a test specimen in the dilatometer while continuously acquiring data, it was observed that there were very small increases in specimen length occurring at room temperature. Some initial bulk thermal expansion measurements were made using a controlled atmosphere dilatometer in which flowing $\mathrm{He}$ gas surrounded the test specimen. Data acquisition was generally terminated when the specimen had cooled to about $70^{\circ} \mathrm{C}$. During one experimental trial, after returning to room temperature in a flowing He environment (while data was still being acquired) room air was allowed into the specimen area which caused a rapid increase in specimen length, Fig. 2 . This paper reports the findings of experiments designed to investigate the observed phenomenon. 


\section{EXPERIMENTAL PROCEDURE}

Compositions chosen for this study are given in the following table:

\begin{tabular}{|l|l||l|l|}
\hline $\mathrm{BS0}$ & $\mathrm{BaZr}_{4} \mathrm{P}_{6} \mathrm{O}_{24}$ & $\mathrm{CS} 25$ & $\mathrm{Ca}_{0.75} \mathrm{Sr}_{0.25} \mathrm{Zr}_{4} \mathrm{P}_{6} \mathrm{O}_{24}$ \\
\hline $\mathrm{BS} 25$ & $\mathrm{Ba}_{1.25} \mathrm{Zr}_{4} \mathrm{P}_{5.5} \mathrm{Si}_{0.5} \mathrm{O}_{24}$ & $\mathrm{CS} 50$ & $\mathrm{Ca} 0.5 \mathrm{Sr}_{0.5} \mathrm{Zr}_{4} \mathrm{P}_{6} \mathrm{O}_{24}$ \\
\hline $\mathrm{BS} 50$ & $\mathrm{Ba}_{1.5} \mathrm{Zr}_{4} \mathrm{P}_{5} \mathrm{SiO}_{24}$ & & \\
\hline
\end{tabular}

BS0 has a positive bulk thermal expansion and is anisotropic, BS25 and CS50 have positive bulk thermal expansion and are isotropic and BS50 and CS25 have generally negative bulk thermal expansion and are anisotropic. These compositions were prepared by the solid state synthesis method from constituent oxides $[1,2]$. The powder derived was then ball milled with appropriate dispersants and binders to form a fine-particle-size slip for casting. Tiles of each composition were cast, bisque fired, sintered and then sliced and ground into test specimens. The CTE test specimens were $3 \mathrm{~mm} \times 4 \mathrm{~mm} \times 25 \mathrm{~mm}$ bars. The sintering conditions were such that the average grain size for all the compositions was 8-12 micrometers. This grain size exceeds the critical grain size necessary for microcrack formation in the anisotropic specimens. The dilatometer used for the test measurements was a Theta, dual push rod, differential dilatometer with a sapphire rod on the reference side. The maximum temperature obtained during thermal expansion measurements was $1250^{\circ} \mathrm{C}$ with a heating/cooling rate of $3-4^{\circ} \mathrm{C}$ per minute, except below $300^{\circ} \mathrm{C}$ during cooling where the rate was slowed by the heat dissipation from the furnace.

To determine what component of room air was responsible for the sudden expansion when opening the dilatometer, runs were made using a He atmosphere, followed by switching to bottled air (very low moisture content, $<1 \mathrm{ppm}$ ) and then to room air with 40 to 60 percent relative humidity. Dilatometer runs were also made such that a controlled humidity atmosphere could be flowed around the test specimen at room temperature after the specimen had been heated to $1250^{\circ} \mathrm{C}$ in a $\mathrm{He}$ environment. Finally, measurements were made where water was dripped onto the specimen while still in the dilatometer where changes in length could be determined as a function of time.

\section{RESULTS AND DISCUSSION}

The measurement of bulk linear thermal expansion is a relatively straight-forward process. A specimen is heated while its length is measured. The thermal expansion 
of the specimen is the change in length divided by the original room temperature $\left(20^{\circ} \mathrm{C}\right)$ length. The coefficient of thermal expansion is this normalized change in length per degree rise in temperature. To increase accuracy, the expansion of the test specimen can be compared to the expansion of a known reference material; this is the case when utilizing a dual push-rod dilatometer. The atmosphere surrounding the test specimen is usually air for oxide ceramics and an inert atmosphere for nonoxide materials. Sometimes helium gas is used to provide better thermal transport from the surrounding heater (furnace) to the test specimen to reduce thermal gradients. The use of helium for this purpose has not been considered to have any effect on the thermal expansion behavior. This is probably true for most materials. When measuring materials which are anisotropic and microcracked, this is not the case. The thermal expansion curves obtained for CS25 $\left(\mathrm{Ca}_{0.75} \mathrm{Sr}_{0.25} \mathrm{Zr}_{4} \mathrm{P}_{6} \mathrm{O}_{24}\right)$ when measured using a helium atmosphere or room air atmosphere are compared in Fig. 3. Note that in the presence of helium that the apparent bulk linear thermal expansion is slightly higher than that measured in an air atmosphere. The point in the cooling portion of the curve where the specimen begins to expand (microcrack) is at a higher temperature in the air atmosphere than helium. The specimen heated in a room air environment recovers more of its initial length before reaching an equilibrium state. It should also be noted that typically the data acquisition is terminated when the specimen temperature falls below $100^{\circ} \mathrm{C}$, where in this case most of the microcracking data would not have been obtained. When the bulk thermal expansion of an isotropic composition is measured using helium and room air atmospheres, there is no detectable difference as shown in Fig. 4, for the isotropic CS50 composition. Since CS50 has isotropic thermal expansion, it does not microcrack upon cooling from its sintering temperature; without microcracks (or residual stress) the atmosphere has no effect. The microstructures of CS25 and CS50 are compared in Fig. 5a and 5b and show the presence of or the lack of microcracks, respectively. Otherwise the microstructure is generally equivalent with equiaxed grains of about the same size and transgranular fracture.

To determine the component in room air that caused the sudden increase in specimen length after previously being heated and cooled in a helium atmosphere, the dilatometer was set up so that the atmosphere could be changed without disturbing the measurement. The expansion curves as a function of time for CS25 and CS50 for differing atmospheric conditions are shown in Fig. 6. For CS25, one run was made entirely in room air. This is compared to a second run where the initial atmosphere was helium until a room temperature equilibrium was reached. At this point dry air (from a bottle of compressed gas having $20 \%$ oxygen and $80 \%$ nitrogen with less than $1 \mathrm{ppm}$ water vapor) was introduced. There was no change in specimen length detected. Finally, room air with approximately $50 \%$ relative humidity was introduced ultimately replacing the dry air. The specimen 
immediately began to expand and increased in length by over $200 \mathrm{ppm}$. The bulk linear thermal expansion curve for CS50, as determined in helium to dry air to humid air, is shown for comparison. The curve obtained for CS50 when run entirely in room air has not been included but would essentially lie on top of the given CS50 expansion curve. The results obtained for all the tested compositions when heated and cooled in helium followed by the introduction of humid room air at room temperature are presented in Fig. 7. The results for CS50 have been omitted, but are essentially the same as the other isotropic composition, BS25. The three anisotropic compositions all display some degree of environmentally induced expansion (microcracking) at room temperature.

From the above results it was concluded that water vapor assisted microcrack opening. Additional confirmation was obtained by comparing the $\mathrm{x}$-ray diffraction patterns of dry and moist CS25 powders, Fig. 8. The only phase detected in both cases was CS25; no hydrated phases were detected. To determine if there was a threshold humidity below which water vapor did not affect crack opening, the dilatometer was set up so that a controlled humidity atmosphere in the specimen area was produced. This was accomplished by splitting the dry air flow and bubbling a portion through a flask of water. After passing through metering valves to control the relative humidity, the two streams of air were recombined before entering the dilatometer. An in-line hygrometer determined the relative humidity of the air stream going into the dilatometer. The results from the controlled humidity experiment is shown in Fig. 9. At low relative humidity (5\%) specimen expansion occurs. This indicates that there is not any threshold level below which some crack opening does not occur. As the relative humidity is increased the specimen expansion increases, rapidly at first, then slows and seems to approach a constant length.

Although moisture in the air assists microcrack opening of a previously heated specimen, not all of the original specimen length is recovered. The specimen is not completely back to its original moisture saturated condition. Originally the specimen was sintered then sliced and ground to the appropriate dimension for measurement. The grinding/slicing operation saturates the specimen with a waterbased coolant. Therefore, to determine if the specimen would return fully to its initial length following a heating cycle to $1250^{\circ} \mathrm{C}$, the following was performed. Four specimens were prepared and included two CS25 and two BS25. The length of each specimen was measured using an optical comparator. One specimen of each composition was then heated to $1250^{\circ} \mathrm{C}$ and cooled in the dilatometer (room air atmosphere). The BS25 specimen returned to its original length while the CS25 specimen had an apparent length change of $-700 \mathrm{ppm}$. All four specimens were again measured using the optical comparator. Finally the two specimens which had 
been thermally cycled in the dilatometer were immersed in water for two hours and again the lengths of all four specimens were determined using the optical comparator. The results from this study are graphically shown in Fig. 10. There is good agreement between the length determined using the optical comparator with the length of the CS25 specimen determined at the end of the dilatometer run. Immersing the CS25 specimen in water caused the specimen to expand, but still not entirely to its original length. From this result it can be concluded that some permanent microcrack healing takes place when the ceramic is heated to $1250^{\circ} \mathrm{C}$.

The other anisotropic compositions displayed similar behavior. Figures 11-13 give the results of measurements, using a BSO specimen, in which the specimen was saturated with water while it was still in the dilatometer. Figure 11 compares the expansion curve with two other expansion curves of the same composition where data acquisition was not continued after the specimens reached $70^{\circ} \mathrm{C}$. The same results when plotted as a function of time are shown in Fig. 12. It can be seen that there is some specimen expansion at room temperature due to the moisture in the air. After approximately 1000 minutes at room temperature, the dilatometer was carefully opened and water dripped onto the specimen. The effect of continually adding drops through specimen saturation is shown in Fig. 13. The specimen has recovered to within $200 \mathrm{ppm}$ of its original length.

\section{CONCLUSIONS}

Several anisotropic compositions of [NZP] type ceramics have been found that exhibit environmentally assisted microcracking. The isotropic compositions are unaffected by their environment. The environmental component responsible for accelerated microcracking has been determined to be water or water vapor. The total amount of microcrack opening is dependent on the relative humidity of the atmosphere. X-ray diffraction analysis did not yield any detectable changes in lattice parameter or crystal structure due to immersion in water. The rapid expansion of CS25 when exposed to humid air after being heated and cooled in a helium atmosphere can explain the failure of large components made from this composition. Other anisotropic compositions are susceptible to this catastrophic failure mechanism and this phenomenon will have to be taken into account when choosing these ceramic materials for specific industrial applications. 


\section{ACKNOWLEDGMENTS}

The authors would like to acknowledge C.R. Hubbard and N.H. Packan for their assistance with the $\mathrm{x}$-ray diffraction results. This research was sponsored by the US. Department of Energy, Assistant Secretary for Energy Efficiency and Renewable Energy, Office of Transportation Technologies, as part of the High Temperature Materials Laboratory User Program and High Temperature Materials Laboratory Fellowship Program, under contract DE-AC05-84OR21400, managed by Martin Marietta Energy Systems, Inc.

\section{REFERENCES}

1. D.K. Agrawal, C.Y. Huang, and H.A. McKinstry, "NZP: A New Family of Low-Thermal Expansion Materials," Intl. J. Thermophysics, 12 [4] 697710 (1991).

2. S. Y. Limaye, D. K. Agrawal, and H. A. McKinstry, "Synthesis and Thermal Expansion of $\mathrm{MZr}_{4} \mathrm{P}_{6} \mathrm{O}_{24}(\mathrm{M}=\mathrm{Mg}, \mathrm{Ca}, \mathrm{Sr}, \mathrm{Ba})$," J. Am Ceram. Soc, 70 C232-C236 (1987).

3. D.A.Hirschfeld, S.M. Van Aken, T.K. Li, Y.P. Yang, and JJ. Brown, "Development of Ultra-Low-Expansion Ceramics: Synthesis, Thermal Expansion, and Thermal Conductivity of $\left(\mathrm{Ca}_{1-\mathrm{x}}, \mathrm{Mg}_{\mathrm{x}}\right) \mathrm{Zr}_{4}\left(\mathrm{PO}_{4}\right)_{6}$," Proceedings of the Annual Automotive Technology Development Contractors' Coordination Meeting, Warrendale, PA, 239-44, (1991).

4. R.W. Rice and R. C. Pohanka "Grain-Size Dependence of Spontaneous Cracking in Ceramics,” J. Am. Ceram. Soc.,62 559-563 (1979).

5. D.P.H. Hasselman, K.Y. Donaldson, E.M. Anderson, and T.A. Johnson, "Effect of Thermal History on the Thermal Diffusivity and Thermal Expansion of an Alumina-Aluminum Titanate Composite," J. Am. Ceram. Soc.,76 2180-84 (1993).

\section{DISCLAIMER}

\footnotetext{
This report was prepared as an account of work sponsored by an agency of the United States Government. Neither the United States Government nor any agency thereof, nor any of their employees, makes any warranty, express or implied, or assumes any legal liability or responsibility for the accuracy, completeness, or usefulness of any information, apparatus, product, or process disclosed, or represents that its use would not infringe privately owned rights. Reference herein to any specific commercial product, process, or service by trade name, trademark, manufacturer, or otherwise does not necessarily constitute or imply its endorsement, recommendation, or favoring by the United States Government or any agency thereof. The views and opinions of authors expressed herein do not necessarily state or reflect those of the United States Government or any agency thereof.
} 


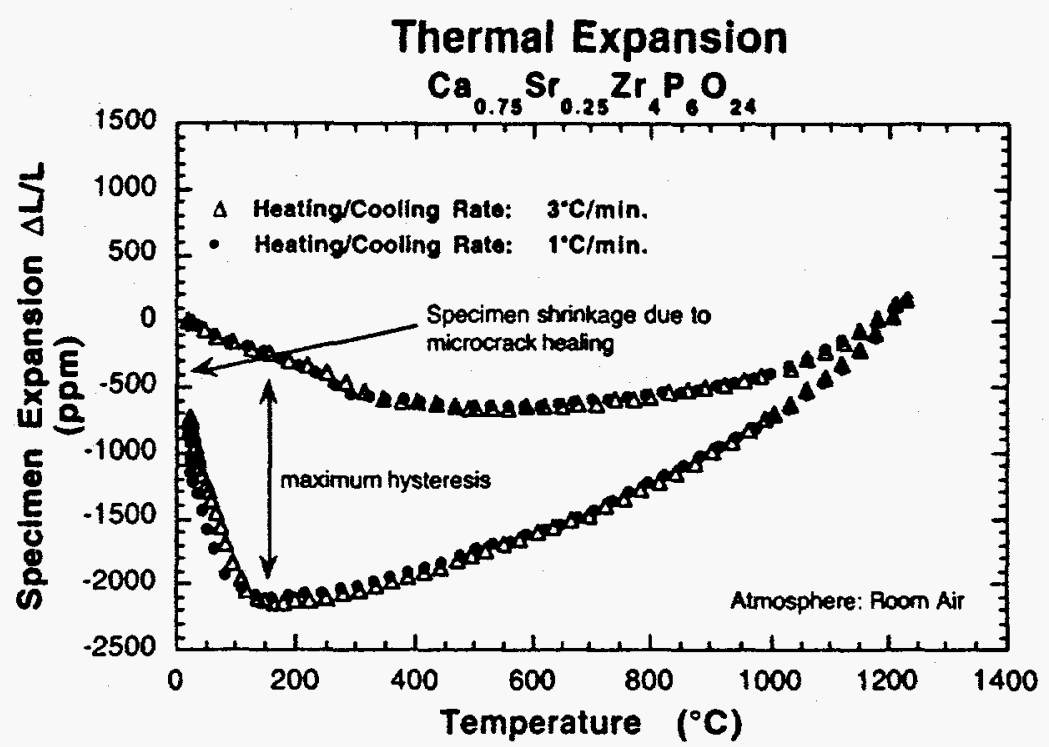

Figure 1. Thermal expansion hysteresis of an anisotropic [NZP] composition and evidence of microcrack healing.

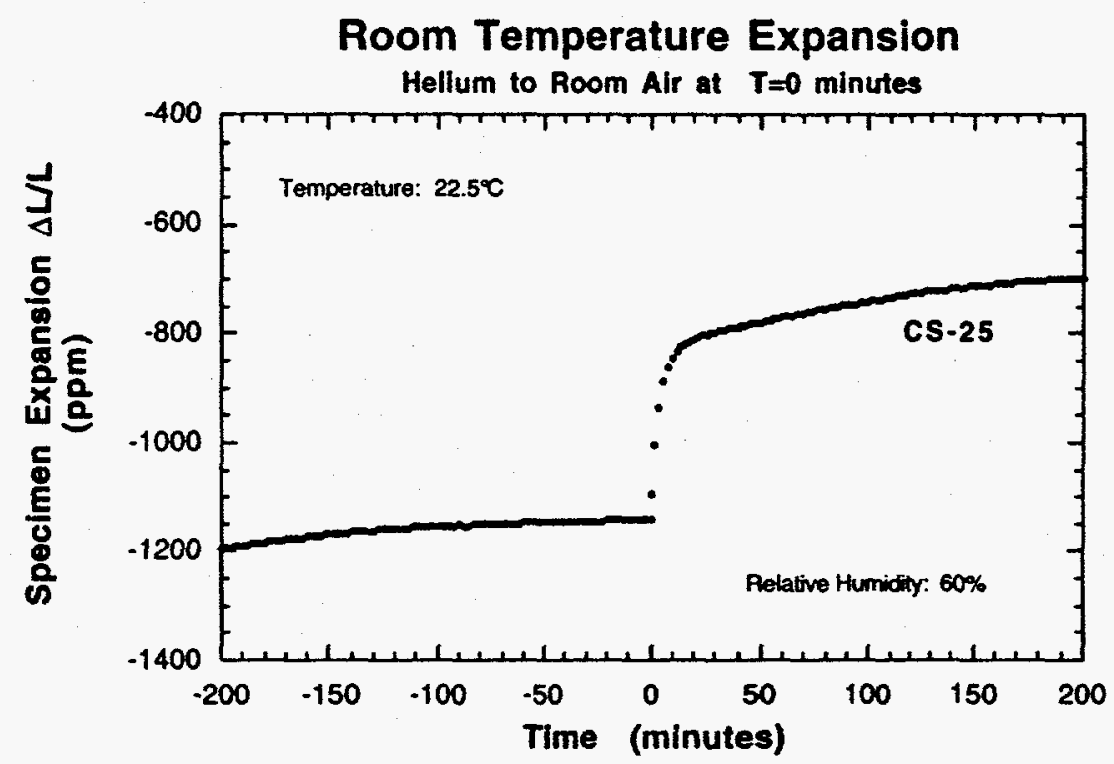

Figure 2. The introduction of room air around the specimen, after heating and cooling in a helium atmosphere, caused a large increase in specimen length. 
Thermal Expansion

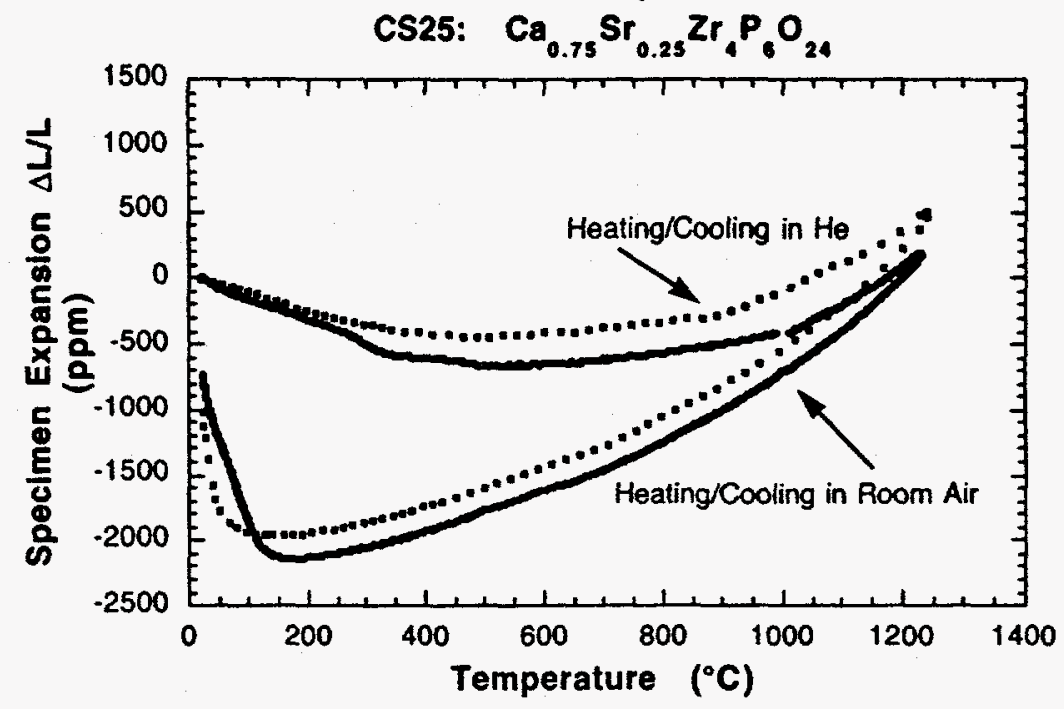

Figure 3. The atmosphere surrounding the test specimen affects the resulting thermal expansion curve of anisotropic [NZP] compositions.

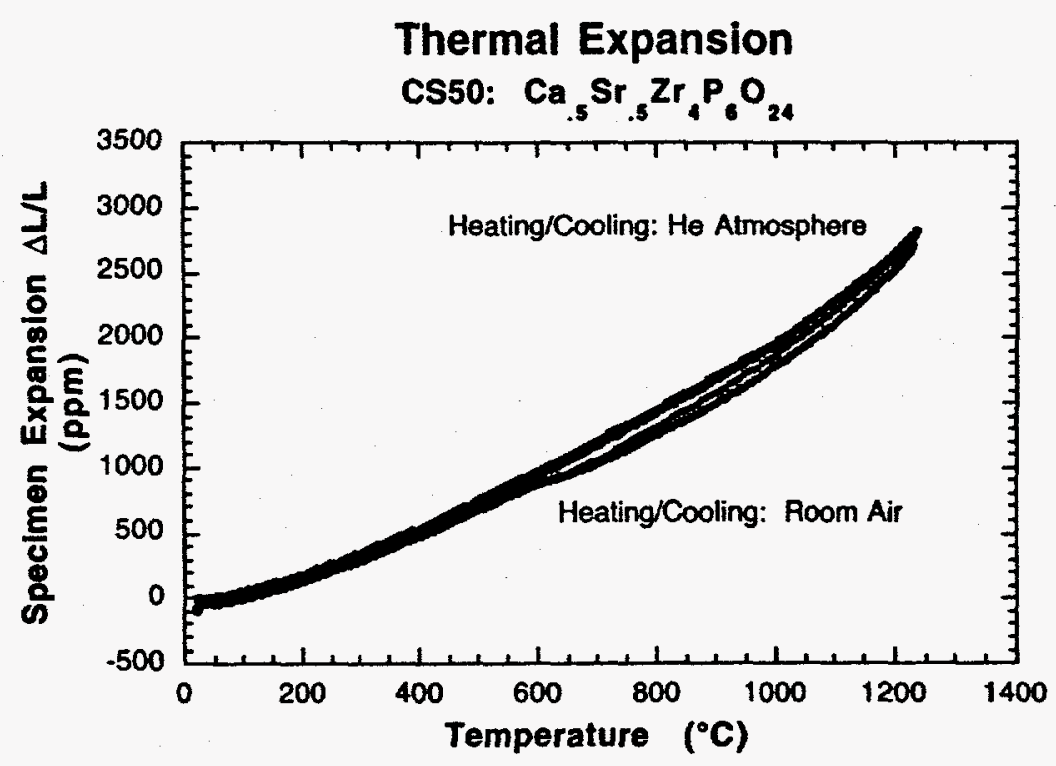

Figure 4. The thermal expansion curves for isotropic compositions are unaffected by the atmosphere in which they are measured. 


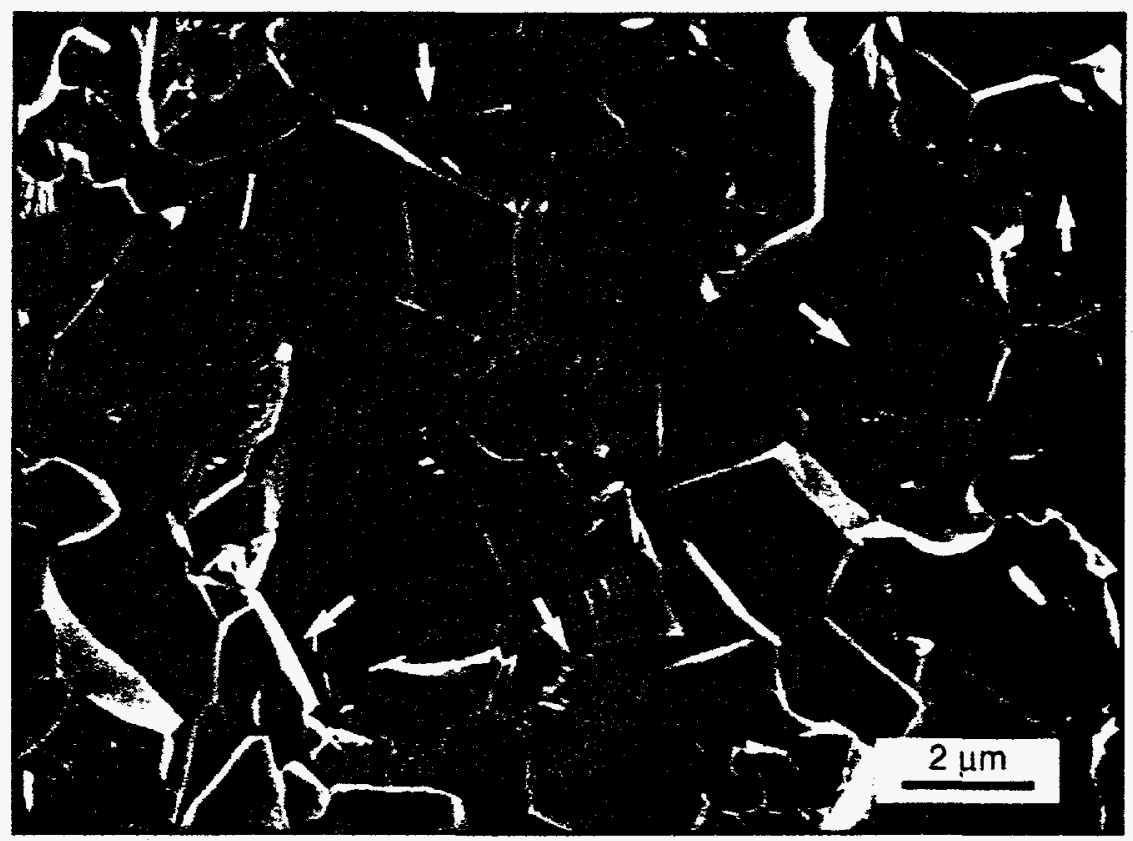

Figure 5a. Microcracking (arrows) is evident for the anisotropic CS25 composition. Approximate average grain size: $8-12 \mu \mathrm{m}$.

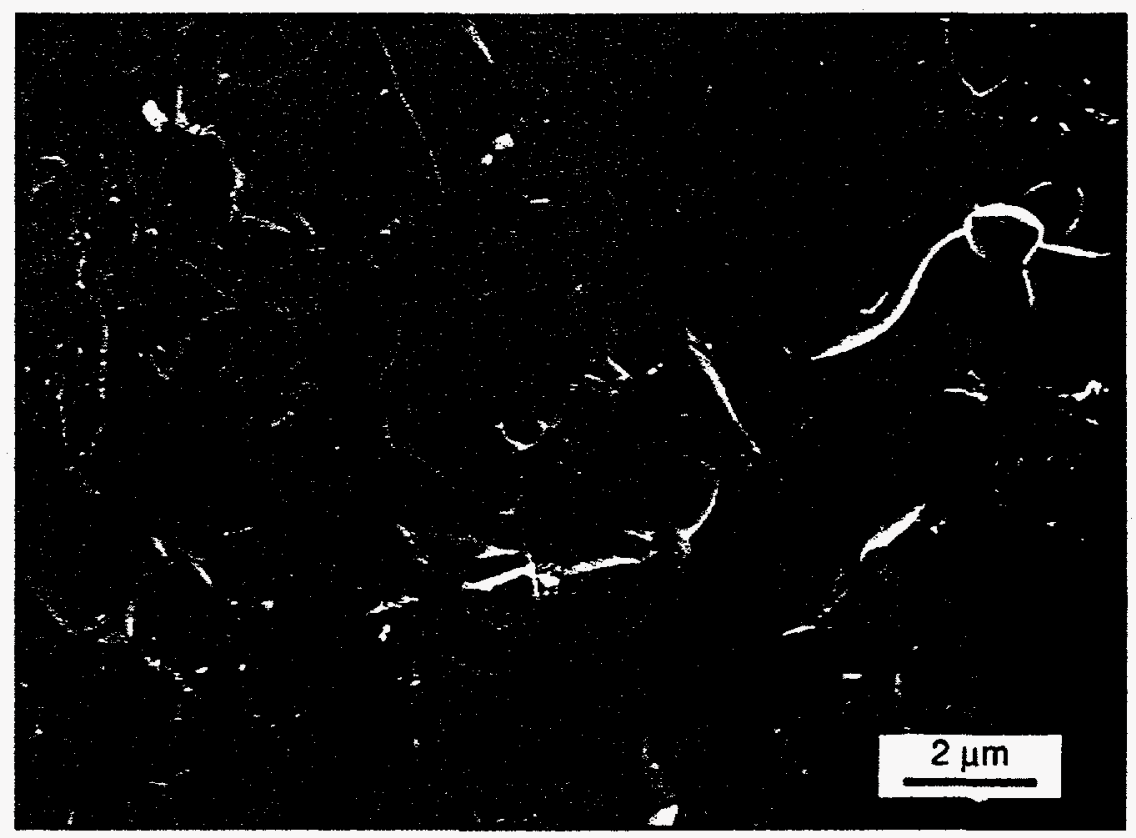

Figure 5b. No evidence of microcracking can be found in the micrographs of CS50. Approximate average grain size: 8-12 $\mu \mathrm{m}$. 


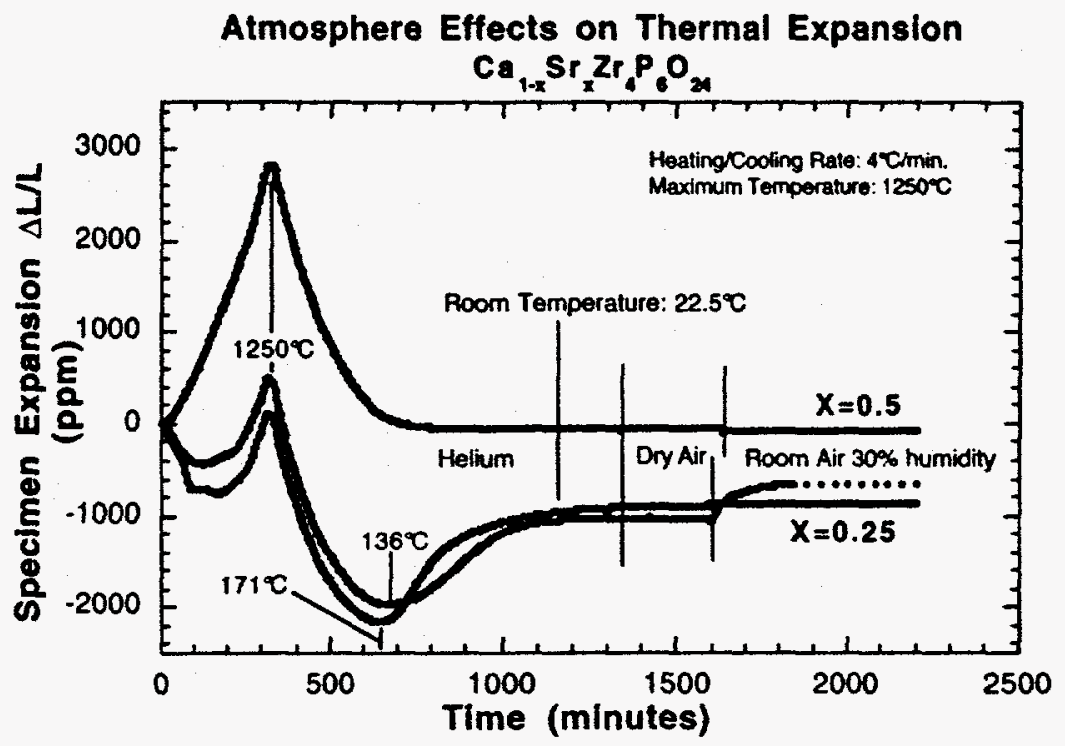

Figure 6. Isotropic CS50 is unaffected by measurement atmosphere, while CS25 undergoes a dramatic expansion when moist air is introduced.

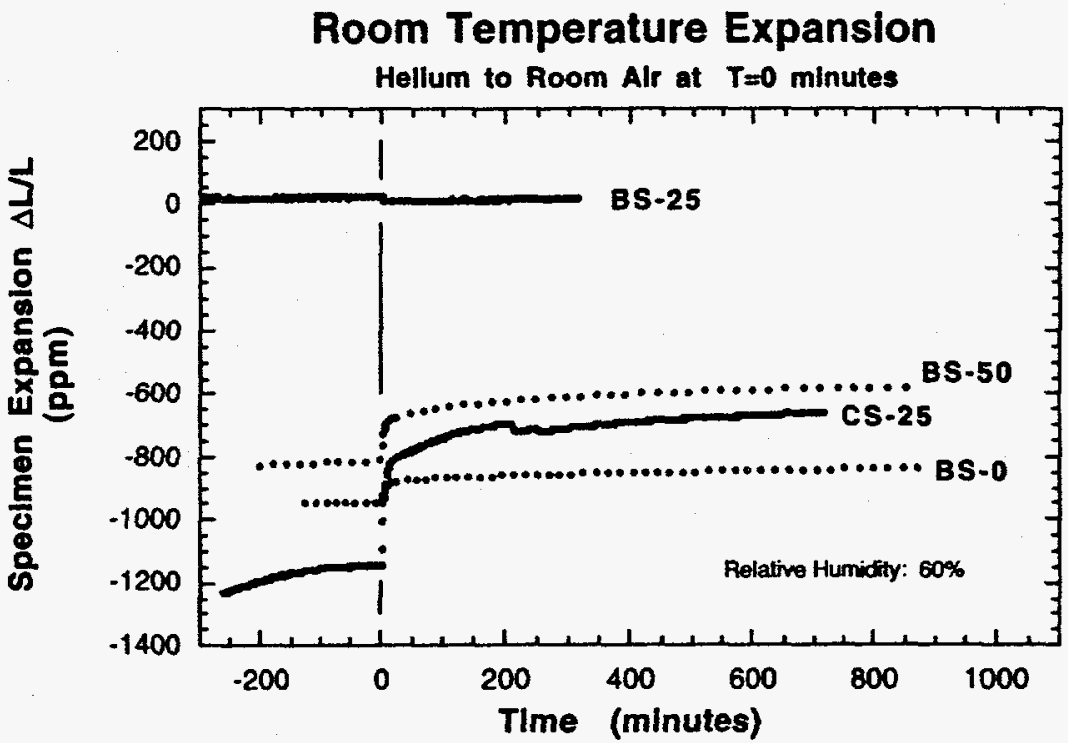

Figure 7. Other anisotropic compositions are susceptible to environmentally assisted microcracking at room temperature. 


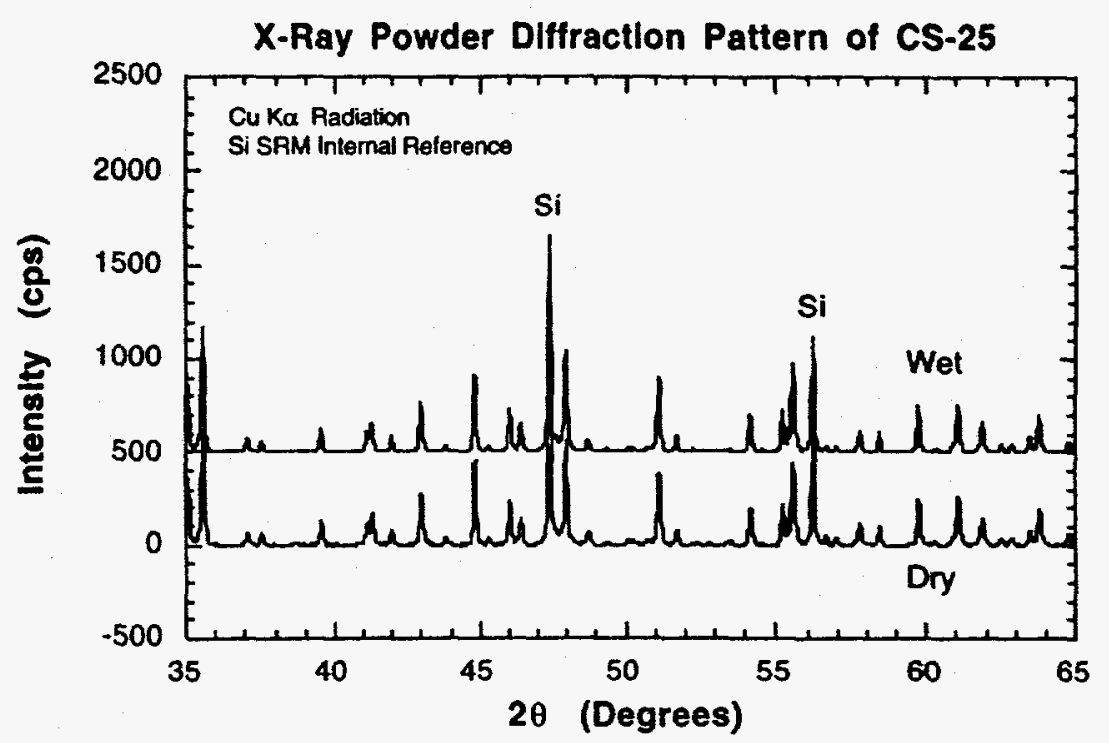

Figure 8. X-ray diffraction analysis indicates that there are no hydrated phases present after the powder is saturated with water.

Effect of Relative Humidity on Room Temperature Microcracking

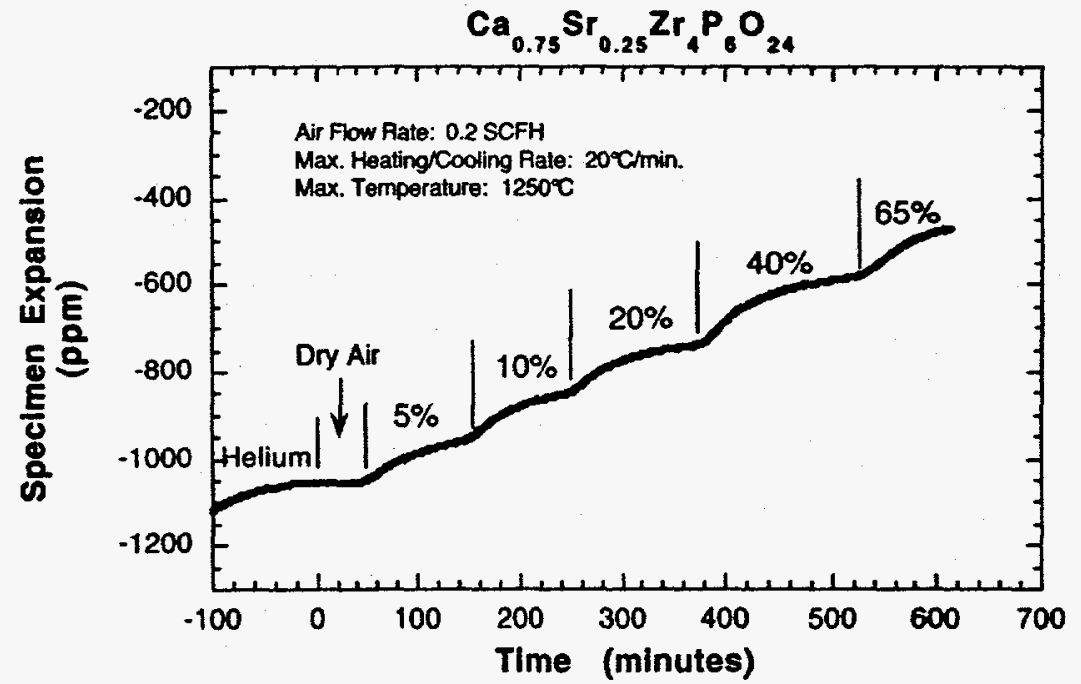

Figure 9. The relative humidity of the test atmosphere affects the amount of room temperature microcracking. 


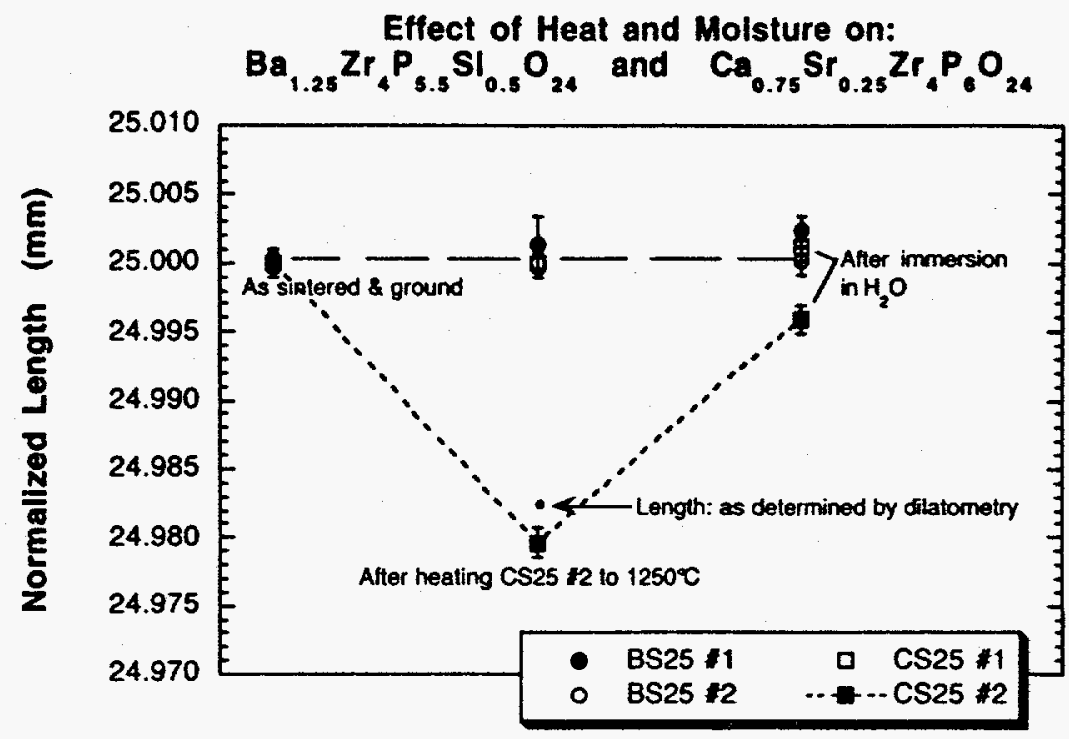

Figure 10. Measurements of specimen length by the optical comparator method are consistent with those obtained from dilatometer measurements.

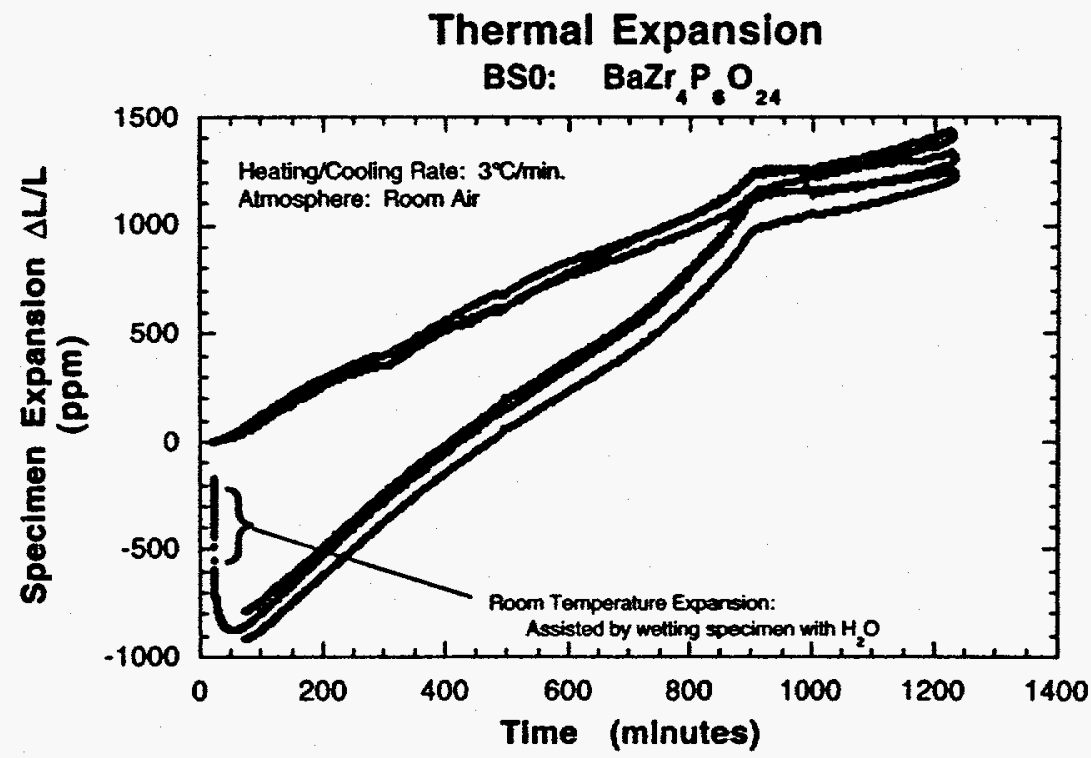

Figure 11. Run to run variation is shown for three BSO specimens. Environmentally assisted microcracking is evident for one specimen during saturation with water. 


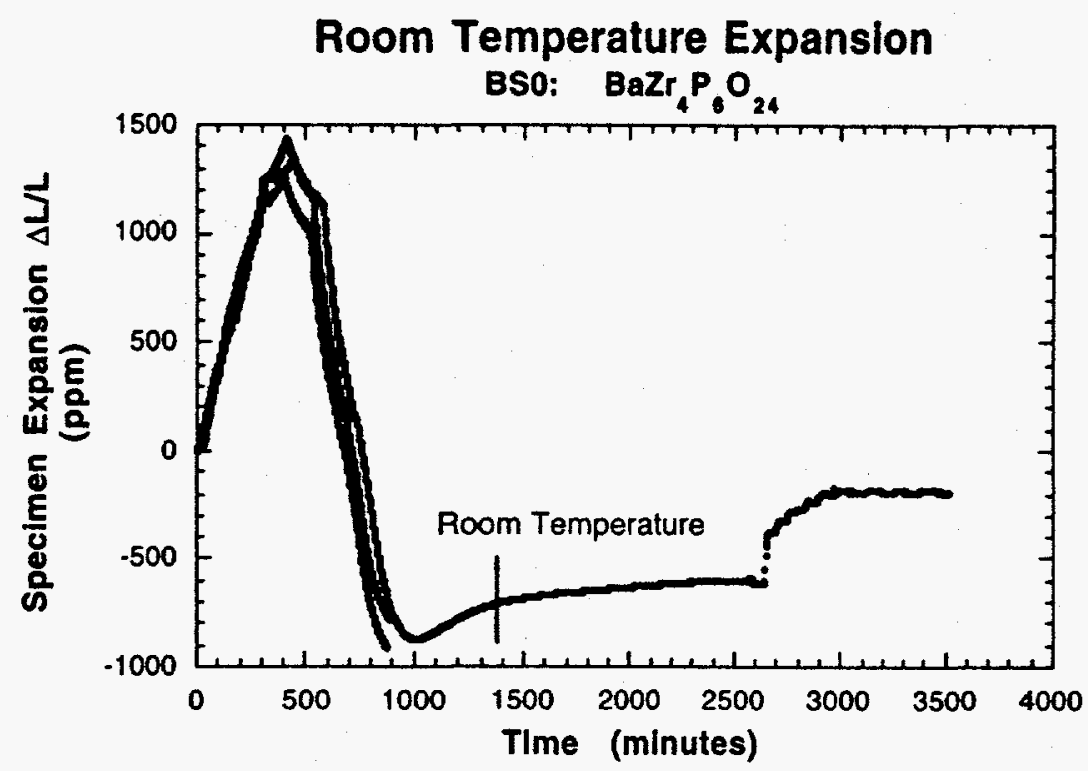

Figure 12. Microcrack opening occurs slowly at room temperature when the specimen is exposed to humid air. The step near the end is due to water dropped on specimen.

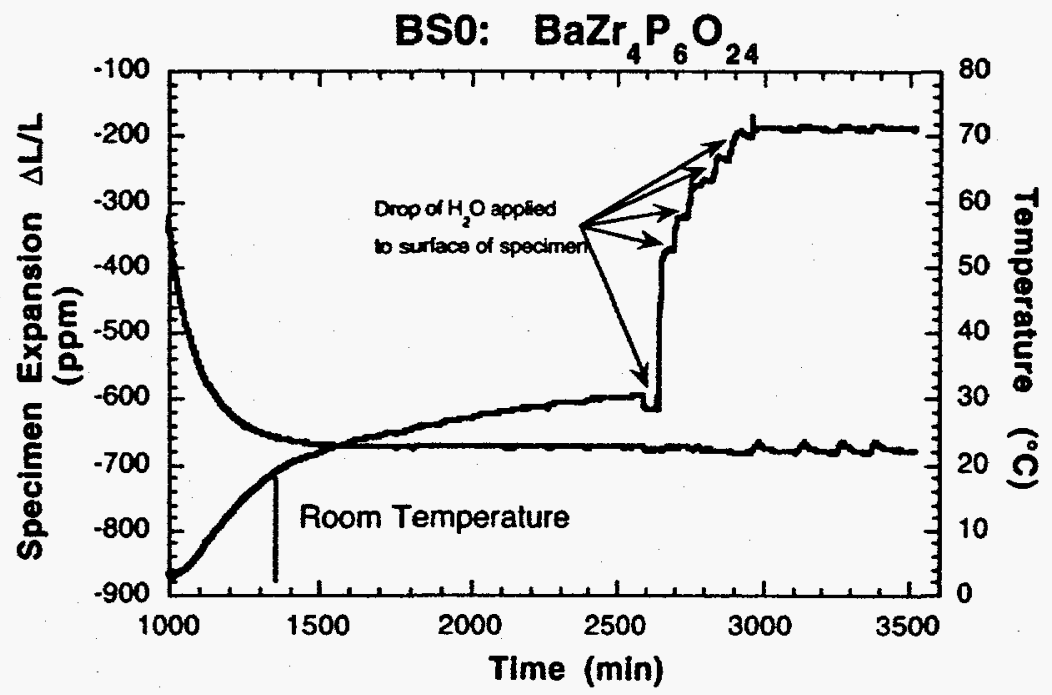

Figure 13. An expanded view of the end of the curve shown in Fig. 12. Saturation with water accelerates the process of microcrack opening and recovers most of the original length. 